\title{
Effect of exposure to morphine throughout gestation on feminine and masculine adult sexual behaviour in golden hamsters
}

\author{
H. M. Johnston ${ }^{1}$, A. P. Payne ${ }^{1}$ and D. P. Gilmore ${ }^{2}$ \\ ${ }^{1}$ Department of Anatomy and ${ }^{2}$ Institute of Physiology, University of Glasgow, \\ Glasgow G12 8QQ UK
}

\begin{abstract}
Adult female hamsters were treated with a long-acting form of morphine before mating and throughout pregnancy; the drug was gradually withdrawn during lactation. The offspring produced were gonadectomized as adults and tested for their ability to display feminine and masculine sexual behaviour after appropriate hormonal priming. Chronic exposure to morphine during development resulted in males that showed an increase in both feminine and masculine sexual behaviour when compared with controls.
\end{abstract}

\section{Introduction}

Exposure to opiates during prenatal or early postnatal development may result in changes in a variety of behaviours including passive avoidance learning (Rech et al., 1980; Casilli and Freeman, 1983), social dominance (Thompson and Zagon, 1983) and open field locomotion (Grove et al., 1979; Lall and Sahoo, 1990).

Other behavioural patterns that might be expected to show alterations following opiate administration include sexually dimorphic patterns (such as sexual behaviour itself) that become dimorphic as a result of the presence or absence of androgen during a short perinatal 'critical period' of central nervous system (CNS) development (Carter et al., 1972; Hayisha and Gorski, 1974; Johnson, 1975; Gray et al., 1976). Opiates might be expected to affect the differentiation process either by suppressing LH secretion (Purohit et al., 1979; Akabori and Barraclough, 1986) or by altering the speed of CNS development (Komblum et al., 1987; Davila-Garcia and Azmitia, 1989). Indeed, Johnston et al. (1992) showed that exposure to opiates for 4 days before or after birth (or over both periods) significantly increased the capacity for feminine sexual behaviour (lordosis) in adult male golden hamsters, but had little effect on their masculine behaviour. This finding suggests that opiate treatment reduces the defeminization process in these males.

However, a difficulty of interpretation was proposed by Lichtblau and Sparber (1984), who suggested that changes in behaviour observed in animals exposed to opiates for a relatively short period during development might not be mediated by opiates themselves, but be caused by their withdrawal. This study was therefore undertaken to investigate whether any behavioural changes occurred in animals exposed to opiates throughout gestation and the early postnatal period and whether these changes were different from those recorded after short-term exposure.

Revised manuscript received 26 March 1993

\section{Materials and Methods}

\section{Animals and treatments}

Chronic morphine-treated animals. Adult female hamsters were housed singly and treated once a day with a long-acting form of morphine, Duromorph (10 $\mathrm{mg} \mathrm{kg}^{-1}$ i.p.), an aqueous suspension of morphine of which $95 \%$ is in microcrystalline form (The Laboratories for Applied Biology Ltd, London). Treatment was given for 4 days before mating and then throughout pregnancy. Morphine was withdrawn during lactation, the dose being reduced by $10 \%$ day $^{-1}$; using this method there were no obvious withdrawal symptoms. The mothers were killed after the pups had been weaned. The pups ( $n=10$ males, $n=12$ females) were not treated separately with morphine as there is evidence that morphine passes to the pups through the milk (Ghodse, 1990).

Control animals. Animals whose mothers were untreated were used as controls ( $n=11$ males, $n=20$ females).

Saline-treated animals. In this group, mothers were injected once a day with $0.1 \mathrm{ml}$ physiological saline i.p. during pregnancy. Pups ( $n=19$ males; $n=15$ females) were given $0.02 \mathrm{ml}$ saline i.p. for 4 days after birth, since there is no evidence that saline given to mothers reaches the pups.

Hormone treatments and tests of feminine and masculine sexual behaviour. Pups were weaned at 21 days after birth and housed with littermates of the same sex, two to three per cage under reversed lighting conditions $(9 \mathrm{~h}$ red light:15 $\mathrm{h}$ bright light). At 3 months of age, they were bilaterally gonadectomized under sodium pentobarbitone anaesthesia (Sagatal, $90 \mathrm{mg} \mathrm{kg}^{-1}$; May and Baker, Dagenham); 2 weeks later, each animal was given a s.c. injection of oestradiol benzoate $(5 \mu \mathrm{g}$ in $0.1 \mathrm{ml}$ oil of arachis; Sigma, Poole) followed $24 \mathrm{~h}$ later by a s.c. injection of progesterone $(500 \mu \mathrm{g}$ in $0.1 \mathrm{ml}$ oil of arachis; 
Table 1. Feminine sexual behaviour as displayed by adult hamsters treated with morphine, or saline, or untreated during gestation

\begin{tabular}{|c|c|c|c|c|c|}
\hline Treatment & Number of animals & Lordosis latency & Total lordosis & Maximum lordosis & Percentage showing lordosis \\
\hline \multicolumn{6}{|l|}{ Males } \\
\hline Untreated & 11 & $482 \pm 63$ & $50 \pm 36$ & $19 \pm 11$ & 27 \\
\hline Chronic morphine-treated & 10 & $118 \pm 55^{* *}$ & $163 \pm 46^{*}$ & $43 \pm 14$ & 90 \\
\hline Saline-treated & 19 & $360 \pm 60$ & $76 \pm 23$ & $28 \pm 8$ & 53 \\
\hline$F$ value & & 6.85 & 2.65 & 1.01 & \\
\hline$P$ value & & $<0.003$ & $<0.08$ & $<0.37$ & \\
\hline \multicolumn{6}{|l|}{ Females } \\
\hline Untreated & 20 & $60 \pm 18$ & $417 \pm 32$ & $265 \pm 39$ & 100 \\
\hline Chronic morphine-treated & 12 & $76 \pm 48$ & $411 \pm 60$ & $285 \pm 58$ & 92 \\
\hline Saline-treated & 15 & $25 \pm 4$ & $431 \pm 44$ & $322 \pm 60$ & 100 \\
\hline$F$ value & & 1.07 & 0.10 & 0.39 & \\
\hline$P$ value & & $<0.35$ & $<0.91$ & $<0.68$ & \\
\hline
\end{tabular}

Values are group means \pm SEM.

* Significantly different from untreated animals $(P<0.05)$.

${ }^{* *}$ Significantly different from untreated animals $(P<0.01)$.

Sigma). Four to six hours after progesterone administration, each animal was tested for its ability to display feminine sexual behaviour when placed with a vigorous stud male. This first test was used to acclimatize the animals to the test conditions and the procedure was repeated I week later. The test lasted for $10 \mathrm{~min}$. Only the data collected during the second test were analysed. The following aspects of behaviour were used in the analysis: (1) the time elapsing between the introduction of the male and the test animal assuming the lordotic position (latency); (2) the total time spent in lordosis during the test session; (3) the longest single episode of lordosis.

After the second test for feminine behaviour, each animal was given a s.c. injection of testosterone propionate $(1.5 \mathrm{mg}$ three times a week; Sigma) for 4 weeks and then tested on three consecutive days for the ability to display masculine sexual behaviour towards a receptive female. The test period was again $10 \mathrm{~min}$ on each day. The specific aspects of behaviour used for analysis were: (1) the time between introduction of the treated animal to the test cage and it mounting the receptive female (average over three tests); (2) the total number of mounts (regardless of orientation) from the three test periods; (3) the total number of intromissions from the three tests; and (4) the total number of genital self-grooms from the three tests.

\section{Statistical analysis}

Data were analysed by one-way analysis of variance $(F)$. After this, intergroup differences were obtained using least significant differences. Tests were carried out using a STATGRAPHICS program (Statistical Graphics Corporation).

\section{Results}

\section{Feminine sexual behaviour}

Normal female hamsters responded to the introduction of a vigorous male by adopting a lordotic posture within $60 \mathrm{~s}$ and remained in that position during most of the test period (417 s out of a possible $600 \mathrm{~s}$ ), and the longest single episode of lordosis lasted an average of $265 \mathrm{~s}$. Neither the saline-treated nor the chronic morphine-treated females differed significantly from this (Table 1 ).

When given oestrogen and progesterone, normal control males did show limited feminine behaviour, but they were much less responsive than were females. Control males took $482 \mathrm{~s}$ to adopt the lordotic posture and spent only $50 \mathrm{~s}$ of a possible $600 \mathrm{~s}$ in lordosis; the longest single episode lasted $19 \mathrm{~s}$. By contrast, males exposed chronically to morphine throughout gestation showed enhanced feminine sexual behaviour. They adopted the lordotic posture within $118 \mathrm{~s}$ of the start of the test and spent a total of $163 \mathrm{~s}$ in lordosis. Although all male groups showed significantly less lordosis than any of the female groups, the time taken by the morphine-treated group to adopt a lordotic stance, and the total time spent in lordosis, was significantly different from that of the controls (Table 1). Overall, only $27 \%$ of control males showed any feminine behaviour, in comparison with $100 \%$ of control female and $90 \%$ of morphine-treated males.

\section{Masculine sexual behaviour}

None of the female groups displayed significant amounts of masculine sexual behaviour (Table 2). Males, however, showed variable levels of mounting with the males treated with morphine showing the greatest amount of masculine sexual behaviour. This group displayed significantly more mounts, genital groomings and intromissions than did the other two male groups.

\section{Discussion}

In the study reported here, no changes in either feminine or masculine sexual behaviour were found in female hamsters exposed to morphine throughout gestation; this result supports some previous findings in rats (Ward et al., 1983), although 
Table 2. Masculine sexual behaviour as displayed by adult hamsters treated with morphine, or saline, or untreated during gestation

\begin{tabular}{|c|c|c|c|c|c|c|}
\hline Treatment & Number of animals & Mount latency & Total mounts & Total intromission & Total grooms & $\begin{array}{r}\text { Percentage sh } \\
\text { mountin }\end{array}$ \\
\hline \multicolumn{7}{|l|}{ Males } \\
\hline Untreated & 11 & $428 \pm 38$ & $20 \pm 6$ & $8 \pm 4$ & $17 \pm 5$ & 82 \\
\hline Chronic morphine-treated & 10 & $266 \pm 45^{*}$ & $45 \pm 10^{* *}$ & $27 \pm 7^{* *}$ & $44 \pm 10^{* *}$ & 100 \\
\hline Saline-treated & 16 & $371 \pm 27$ & $14 \pm 2$ & $2 \pm 1$ & $9 \pm 2$ & 100 \\
\hline$F$ value & & 4.42 & 8.04 & 10.3 & 10.13 & \\
\hline$P$ value & & $<0.02$ & $<0.001$ & $<0.001$ & $<0.001$ & \\
\hline \multicolumn{7}{|l|}{ Females } \\
\hline Untreated & 12 & $564 \pm 24$ & 0.25 & 0 & 1 & 17 \\
\hline Chronic morphine-treated & 13 & $572 \pm 12$ & 1 & 0 & 1 & 38 \\
\hline Saline-treated & 15 & $520 \pm 29$ & $3 \pm 1$ & 0 & 2 & 40 \\
\hline$F$ value & & 1.48 & 2.58 & 0.43 & 0.53 & \\
\hline$P$ value & & $<0.24$ & $<0.89$ & $<0.65$ & $<0.59$ & \\
\hline
\end{tabular}

Values are group means \pm SEM.

*Significantly different from untreated animals $(P<0.05)$.

${ }^{* *}$ Significantly different from untreated animals $(P<0.01)$.

Vathy et al. (1983) did note a reduction in feminine sexual behaviour in female rats exposed to morphine on days 5-12 of gestation. By contrast, exposing male hamsters to morphine throughout gestation resulted in a very significant increase in the number of animals showing feminine sexual behaviour, together with an increase in the amount of feminine behaviour shown. Thus there was a considerable reduction in lordosis latency and an increase in total lordosis, a similar trend to that reported in male rats after prenatal morphine treatment (Ward et al., 1983). These findings suggest that the process of defeminization may have been compromised as a result of morphine treatment. In a study on hamsters (Johnston et al., 1992), males treated with morphine for 4 days after birth or over 8 days, covering both pre- and postnatal exposure, showed an increase in feminine behaviour. As an increase in feminine sexual behaviour also occurs in males whose androgen concentrations are suppressed (Whalen and Edwards, 1967), it is possible that circulating androgen concentrations in the males in the experiment reported here may have been reduced as a result of opiate exposure. However, it must be remembered that the masculine sexual behaviour in these males was significantly higher than that observed in either of the two control groups. Since the capacity for masculine sexual behaviour also depends on androgen concentrations being relatively high during the critical period for masculinization, this could rule out the possibility that the changes in feminine behaviour are caused by an opiate-induced suppression of androgens and alternative mechanisms must be considered.

Opioid receptors are first detectable within the rat CNS on embryonic day 14 (Kent et al., 1982). Their pattern of distribution changes during fetal development (Petrillo et al., 1987) and opiate exposure during this period has been shown to alter the rate and distribution of receptor ontogeny (Tempel et al., 1988). During development, many neurotransmitters (including the endogenous opioids) are considered to be involved in the control and direction of neurogenesis and synaptogenesis (Hauser et al., 1989). In particular, exposure to exogenous opiates has been shown to delay and inhibit neuronal growth and synaptogenesis both in vivo and in vitro (Seidler et al., 1982; Hammer et al., 1989). Changes in receptor distribution and ontogeny brought about by morphine administration might therefore interfere with these processes. In the experiment reported here, pups were exposed to morphine throughout development, as opiates are known to cross the placental barrier and accumulate in the fetal plasma and brain (Johnston et al., 1992). By contrast, exposure of pups to the drug after birth could only be through the milk, and drug administration was phased out completely over the first few days of lactation. Defeminization occurs postnatally in hamsters (De Bold and Whalen, 1975). Thus, if neural development was delayed as a result of opiate exposure, the systems involved in defeminization might reach maturity too late in the critical period for the process to be completed. This would result in males that showed higher than normal levels of lordotic behaviour. It is not clear at present why the same males show higher than normal levels of masculine sexual behaviour.

In conclusion, we have shown that chronic exposure to morphine has the same effect on the feminine sexual behaviour of male hamsters as does acute exposure and we therefore suggest that these alterations in behaviour are not due to withdrawal of the drug. In addition it would appear that, in this species at least, the increase in feminine sexual behaviour is not due to any opiate-induced reduction in androgens since masculine behaviour was not reduced.

This project was funded by Wellcome research grant no. 16768/1.5/2B38. The authors thank The Laboratories for Applied Biology Ltd, London for the gift of Duromorph.

\section{References}

Akabori A and Barraclough CA (1986) Effects of morphine on luteinizing hormone secretion and catecholamine turnover in the hypothalamus of estrogen-treated rats Brain Research 362 221-226

Carter CS, Clemens LG and Hoekema DG (1972) Neonatal androgen and adult sexual behaviour in the golden hamster Physiology and Behaviour 9 93-95 
Casilli PM and Freeman PR (1983) The effects of prenatal exposure to methadone on retention of passive-avoidance response Teratology 27 A37

Davila-Garcia MI and Azmitia EC (1989) Effects of acute and chronic administration of leu-enkephalin on cultured 5HT neurones: evidence for opioids as inhibitory neuronal growth factors Developmental Brain Research 49 97-103

De Bold JF and Whalen RE (1975) Differential sensitivity of mounting and lordosis control systems to early androgen treatment in male and female hamsters Hormones and Behaviour 6 197-209

Ghodse H (1990) Problems of maternal substance abuse. In Substance Abuse and Dependence pp 216-231 Eds H Ghodse and D Maxwell. Macmillan Press, Basingstoke

Gray GD, Davis HN and Dewsbury DA (1976) Masculine sexual behaviour of male and female rats following perinatal manipulation of androgen: effects of genital anaesthetization and sexual experience Hormones and Behaviour 7 317-321

Grove LV, Etkin MK and Rosencrans JA (1979) Behavioural effects of fetal and neonatal exposure to methadone in the rat Neurobehavioural Toxicology 1 $87-95$

Hammer RP, Jr, Ricalde AA and Seatriz JV (1989) Effects of opiates on brain development Neurotoxicology 10 475-484

Hauser KF, McLaughlin DJ and Zagon IS (1989) Endogenous opioid systems and the regulation of dendritic growth and spine formation Journal of Comparative Neurology 281 13-22

Hayisha S and Gorski RA (1974) Critical exposure for androgenization by intracranial crystals of testosterone propionate in neonatal female rats Endocrinology 94 1161-1163

Johnson WA (1975) Neonatal androgenic stimulation and adult sexual behaviour in male and female golden hamsters Journal of Comparative Physiology and Psychology 89 433-441

Johnston HM, Payne AP and Gilmore DP (1992) Perinatal exposure to morphine affects the adult sexual behavior of the male golden hamster Pharmacology Biochemistry and Behavior 42 41-44

Kent J, Pert C and Herkenham M (1982) Ontogeny of opiate receptors in the rat forebrain: visualization by in-vitro autoradiography Developmental Brain Research 2 487-504
Kornblum HI, Loughlin SE and Leslie FM (1987) Effects of morphine on luteinising hormone secretion and catecholamine turnover in the hypothalamus of oestrogen-treated rats Brain Research 362 221-226

Lall SB and Sahoo RN (1990) Physical and behavioural development in rats after prenatal exposure to diazepam Indian Journal of Physiology and Pharmacology 34 17-22

Lichtblau L and Sparber S (1984) Opioids and development: a perspective on experimental models and methods Neurobehavioural Toxicology and Teratology $63-8$

Petrillo P, Tavani A, Verotta D, Robson LE and Kosterlitz HW (1987) Differential postnatal development of $\mathrm{m}, \mathrm{d}$, and $\mathrm{k}$ - opioid binding sites in rat brain Developmental Brain Research 31 53-58

Purohit V, Singh HH and Ahluwalia BS (1979) Evidence that the effects of methadone and marihuana on male reproductive organs are mediated at different sites in rats Biology of Reproduction 20 1039-1044

Rech RH, Lomuscio G and Algeri S (1980) Methadone exposure in utero: effects on brain biogenic amines and behaviour Neurobehavioural Toxicology 2 75-78

Seidler FJ, Whitmore WL and Slotkin TA (1982) Delays in growth and biochemical development of rat brain caused by maternal methadone administration: are the alterations in synaptogenesis and cellular maturation independent of reduced maternal food intake? Developmental Neuroscience 5 13-18

Tempel A, Habas J, Paredes W and Barr GA (1988) Morphine-induced downregulation of m-opioid receptors in neonatal rat brain Developmental Brain Research 41 129-133

Thompson CI and Zagon IS (1983) Reduced social dominance in adult rats perinatally exposed to methadone Neurobehavioural Toxicology and Teratology 5 17-21

Vathy IU, Etgen AM, Rabii J and Barfield RJ (1983) Effects of prenatal exposure to morphine sulfate on reproductive function of female rats Pharmacology, Biochemistry and Behavior 19 777-780

Ward OB, Jr, Orth JM and Weisz J (1983) A possible role of opiates in modifying sexual differentiation Monographs in Neural Science 9 194-200

Whalen RE and Edwards DA (1967) Hormonal determinants of development of masculine and feminine behaviour in male and female rats Anatomical Record $157 \quad 173-180$ 